\title{
Competências para a gestão de Unidades Básicas de Saúde: percepção do gestor
}

COMPETENCIAS PARA LA GERENCIA DE CENTROS DE SALUD: PERCEPCIÓN DE LOS GESTORES

\section{Adriana Maria André1, Maria Helena Trench Ciampone ${ }^{2}$}

\section{RESUMO}

$\mathrm{O}$ artigo descreve uma investigação realizada para conhecer o perfil de competências dos gestores de Unidades Básicas de Saúde (UBS) e verificar se favorecem a implementação dos novos modelos assistenciais e gerenciais propostos. A modalidade pesquisa-ação foi utilizada por se tratar de estudo social com base empírica, na qual os investigadores e sujeitos do estudo interagiam no cenário onde foi realizado. Participaram dezenove gestores de uma Supervisão Técnica de Área da Secretaria Municipal de Saúde de São Paulo. Foram realizadas entrevistas e grupo focal. Os temas disparadores do grupo foram gerados pela análise das entrevistas visando à problematização. As evidências mostraram que a percepção dos gestores em relação às competências para gerir uma UBS baseia-se em uma visão simplista que influencia diretamente o modo de operacionalização das estratégias e na dinâmica das equipes, dificultando a implementação de propostas mais eficazes.

\section{DESCRITORES}

Administração de Serviços de Saúde.

Gerência.

Competência profissional.

\begin{abstract}
The objective of this research was to identify the competences profile of the healthcare Unit Manager's and verify if it facility the implementation of the new clinical and managerial models proposed. To understand the changes in the health care management, the authors have analyzed the social transformation in their historical and dynamic context; the researchaction methodology was chosen because the authors are involved cooperatively in the scenery. The subjects of this study were nineteen managers from one of the Health Technical Supervision in Health of São Paulo City. The data was gathered by individual interviews and by means of a focus group. Results showed that the perceptions of current managers regarding the competences to manage a Basic Healthcare Unit involving a simplistic view that directly influences the implementation of strategies and the dynamics of working teams, to becoming processes no efficient.
\end{abstract}

\section{KEY WORDS}

Health Services Administration. Management.

Professional Competence.

\section{RESUMEN}

El artículo describe una investigación hecha para conocer el perfil de competencias de los gestores de Centros de Salud y verificar si esas favorecen la implementación de los nuevos modelos asistenciales y gerenciales. Se eligió la modalidad investigación-acción, por ser un estudio social con base empírica, en la cual los investigadores y los sujetos de la investigación interactúan en el escenario. Se efectuaron entrevistas y grupo focal. Participaron diecinueve gestores de una Supervisión Técnica de Área de la Secretaría Municipal de Salud de São Paulo. Los temas motivadores del grupo focal se generaron a partir del análisis de las entrevistas, para propiciar la problematización. Fue evidenciado que la percepción de los gestores, al respecto de las competencias para gestionar un Centro de Salud, son basadas en una visión simplista, influenciando directamente el modo de operar las estrategias y la dinámica de los equipos, contribuyendo a la ineficacia de las propuestas.

\section{DESCRIPTORES}

Administración de los Servicios de Salud.

Gerencia.

Competencia profesional.
* Extraído da dissertação "Competências para gestão de Unidades Básicas de Saúde: percepção do gestor, Escola de Enfermagem, Universidade de São Paulo, 2006.

1 Mestre em Enfermagem na área de Administração em Serviços de Enfermagem pela Escola de Enfermagem, Universidade de São Paulo (EEUSP).

Assessora Técnica de Planejamento da Coordenadoria Regional de Saúde Sul de São Paulo (licenciada). Assessora da

Superintendência da Fundação Getúlio Vargas (IDE/FGV-SP). São Paulo, SP, Brasil. adriana.andre@fgv.br 2 Doutora em Psicologia. Professora Titular da Escola de

Enfermagem, Universidade de São Paulo (EEUSP). Líder do Grupo de Estudos e Pesquisas sobre

Aspectos Psicossociais do Ensino e do Gerenciamento em Saúde. Pesquisadora do CNPq. Chefe do Departamento de Orientação Profissional da Escola de Enfermagem,

Universidade de São Paulo (EEUSP). São

Paulo, SP, Brasil. mhciamp@usp.br 


\section{INTRODUÇÃO}

A correlação entre os modelos de gestão dos setores públicos e privados permite verificar que nos serviços públicos prevalecem modelos de gestão tradicionais, ancorados em estruturas rígidas que definem hierarquias verticalizadas e processos decisórios centralizados.

Ao focarmos o setor público de saúde e, mais especificamente, o papel dos gestores de Unidades Básicas de Saúde é importante ressaltar que no nível local eles são reféns de regulamentações que restringem severamente, no plano formal, sua autonomia. Dentre outras limitações, não contam com orçamento próprio para gerir recursos humanos, contratar, descontratar, realizar negociações salariais ou instalar mecanismos de incentivo ou sanção condicionados à produção de metas quanti ou qualitativas. Os servidores concursados não podem ser demitidos e, para que ocorra uma simples transferência, o gestor depende da anuência de instâncias de âmbito regional e central, no caso da organização do Município de São Paulo.

No caso de unidades que contam com o Programa de Agentes Comunitários de Saúde (PACS) e o Programa de Saúde da Família (PSF) as contratações são feitas sob o regime da Consolidação das Leis do Trabalho (CLT) ou pelas organizações Sociais de Saúde denominadas instituições parceiras. Isto facilita o processo de contratação e demissão, mas ambas as ações devem ser aprovadas pelas instâncias superiores. Contudo, o fato de ter no mesmo local de trabalho funcionários que exercem funções semelhantes e que recebem salários diferentes gera dificuldades na gestão dos recursos humanos.

Para que ocorra um eventual fechamento da Unidade, seja para manutenção, reforma ou treinamento o gestor deve pedir permissão à instância superior e, caso aprovado, deve aguardar a publicação com antecedência no diário oficial do município.

Assim, qualquer iniciativa mesmo visando ao cumprimento da finalidade de melhoria do serviço deve ser discutida com a Supervisão Técnica de Área, com o Conselho Gestor da unidade e com a Coordenadoria Regional de Saúde ${ }^{(1)}$.

Assim, pode-se afirmar que o sistema continua referendando que os gestores sofram processo de desconcentração, definida como a delegação de responsabilidade sem a equivalente delegação de poder decisório, transferindo-se responsabilidades pela implementação de decisões centralizadas, porém sem a prerrogativa de poder modificá-las conforme a necessidade local ${ }^{(2)}$.
Além das limitações de ordens práticas, financeiras e as ligadas à legislação municipal, existe a subjetividade permeando as relações de poder advindas da dimensão político-partidária. A ascensão à posição de gestor de UBS não é decorrente de avaliação meritória, mas proveniente de indicação política, relações de amizade e confiança mantidas com o superior hierárquico imediato ou com instâncias políticas superiores. Por exemplo, cada vez que muda o Prefeito, ocorrem indicações para cargos considerados de confiança, que se estendem também aos escalões técnicos no âmbito dos serviços de saúde, gerando descontinuidade de ações em função de interesses partidários e não em função de avaliações ancoradas em necessidades reais.

\section{REVISÃO TEÓRICO-CONCEITUAL}

Entre os estudiosos da área de Recursos Humanos, um dos conceitos de competência que tem sido bastante utilizado consiste em:

conjunto de conhecimentos, habilidades e atitudes que afetam a maior parte do trabalho de uma pessoa e que se relacionam com o desempenho no trabalho; a competência pode ser mensurada, quando comparada com padrões estabelecidos e desenvolvida por meio de treinamento(3).

Os conhecimentos e habilidades requeridos pelo profissional que vai assumir ou que já assume a função de gestor são perpassados pelas dimensões técnica, administrativa, política, ética e psicossocial ${ }^{(4)}$.

Há consenso entre estudiosos da Admiistração, que conceitos como de gestão estratégica se aplicam plenamente aos serviços de saúde e são fundamentais ao processo gerencial: definição da missão, análise dos recursos, necessidades e cenários, desenvolvimento e monitoramento dos planos de ação, elaboração de políticas para conferir viabilidade aos planos e processos de avaliação contínua, são alguns exemplos de instrumentos fundamentais ao campo do gerenciamento ${ }^{(5)}$.

Também há consenso de que o processo decisório envolve não somente a análise dos dados, dos processos, dos recursos, da relação custo-benefício como também da base de suporte político que o gestor deve ter para a aprovação e sustentação de planos de ação.

A produção do conhecimento na área de administração de serviços de saúde indica que o gestor enquanto líder deve saber trabalhar com sua equipe de maneira a desenvolver os conhecimentos e habilidades do grupo, buscando sinergia e desenvolvimento contínuo do mesmo ${ }^{(4-6)}$. 
Considerando a gestão de serviços de saúde, compreende-se o processo saúde-doença como:

\begin{abstract}
a síntese de um conjunto de determinações que operam numa sociedade concreta, produzindo, nos diferentes grupos sociais o aparecimento de riscos ou potencialidades característicos, por sua vez manifestos na forma de perfis ou padrões de doenças ou saúde e que a qualidade de vida a que cada grupo sócio-econômico está exposto é diferente e, portanto, é igualmente diferente a sua exposição a processos de risco que produzem o aparecimento de doenças e formas de morte específicas, assim como seu acesso a processos benéficos ou potencializadores da saúde e da vida ${ }^{(7)}$.
\end{abstract}

Cabe ressaltar que o modelo assistencial para intervir nesse processo tem dimensões políticas, administrativas e técnicas. Diz respeito à consecução de diretrizes da política de saúde, que devem traduzir-se num arranjo jurídico, organizacional e técnico direcionado aos problemas e necessidades de saúde de uma dada realidade epidemiológica. Assim, não é apenas um conjunto de práticas, mas inclui as concepções que as precedem e segundo as quais elas são pensadas, operadas e organizadas. Essas práticas se organizam e se conformam na própria dinâmica social e política e nos espaços possíveis dos projetos e dos interesses dos grupos sociais, traduzindo-se no modo como o Estado e a sociedade civil, incluindo as instituições de saúde, as organizações de trabalhadores, as empresas que atuam no setor, se organizam para produzir os serviços de saúde. Assim, a gestão do serviço de saúde legitima um conjunto de intervenções como modo operatório de um dado modelo. $\mathrm{O}$ modelo de gestão empregado permite ou não transitar de um modelo assistencial pautado na atenção médica para um modelo de atenção à saúde; de um modelo tradicional (flexneriano) para um modelo de produção social da saúde, ou seja, de um modelo clínico para um modelo epidemiológico; da lógica da programação tradicional para a da organização tecnológica do processo de trabalho em saúde.

Estudos revelaram que o sistema de saúde brasileiro atualmente é palco da disputa e da coexistência de modelos assistenciais diversos, cujas características derivam da tensão entre a tendência de reprodução conflitiva dos modelos hegemônicos ao lado daqueles que buscam transformações ${ }^{(5)}$.

Apoiando-se nessas considerações, o gerenciamento local de saúde deve ser desenvolvido por profissional competente, capaz de liderar e agregar valor aumentando o potencial de sua equipe e conjugando esforços para utilizar recursos financeiros, tecnológicos, materiais e humanos de modo a aumentar a resolutividade do serviço na área de abrangência, em conformidade com o modelo assistencial pautado na epidemiologia social.

Para conduzir processos de mudança nas organizações, dentre as competências do gestor local, a de liderança é mencionada por estudiosos da Administração, como indis- pensável. Essa competência é definida como a capacidade de reunir pessoas em torno de projetos, metas, objetivos e processos de trabalho, obtendo resultados significativos, motivação do grupo e clima de trabalho favorável ${ }^{(8)}$.

Fica evidente que para operacionalizar um dado modelo assistencial há necessidade de desenvolver localmente um modelo gerencial pertinente que seja capaz de favorecer as ações fundamentais à sustentação do processo.

Isso posto, os objetivos da presente investigação consistiram em: 1) conhecer a percepção dos profissionais que exercem a gestão de Unidades Básicas de Saúde acerca de quais são as competências necessárias à operacionalização de novas práticas de gestão que privilegiem o coletivo e o trabalho participativo; 2) problematizar se a formação e o preparo dos gestores influenciam o modo de operacionalização das estratégias e a dinâmica das equipes envolvidas nos serviços, tendo em vista a composição de um perfil de competências gerenciais compatíveis com os novos modelos de gestão em saúde.

\section{MÉTODO}

Nesse trabalho, optamos pela pesquisa-ação, uma modalidade de pesquisa social com base empírica que envolve pesquisadores e sujeitos de modo cooperativo e participativo. Este tipo de orientação metodológica permite o aumento do conhecimento ou do nível de consciência do grupo envolvido no processo, acerca do objeto de pesquisa $^{(9-10)}$.

Assim, a vertente metodológica adotada foi a da pesquisa social, na perspectiva qualitativa, tendo como base de análise dos dados a dialética, pois entendemos que não se compreende a mudança no processo de gerenciamento da assistência dos serviços de saúde, sem levar em conta o processo histórico em seu dinamismo, provisoriedade e transitoriedade social $^{(9)}$.

Os sujeitos da pesquisa foram os gestores de 19 Unidades de Saúde de uma das Supervisões Técnicas de Área da Secretaria Municipal de Saúde de São Paulo. Foram seguidas duas etapas: na primeira realizamos entrevistas e na segunda, grupo focal. Para a entrevista foram convidados 06 gerentes, 03 gerentes que fizeram o curso Gerenciamento de Unidades de Saúde (GERUS) ou outro curso de gerenciamento e 03 gerentes que não fizeram nenhum curso específico na área gerencial. A partir da análise do material proveniente da transcrição das falas gravadas durante as entrevistas, realizamos uma leitura flutuante do conjunto das comunicações que foi seguida pela constituição do corpus, desvelando os núcleos de sentido que constituíram os temas disparadores do encontro de grupo focal. Neste, consideramos que os gerentes presentes eram porta-vozes da problemática e percepções dos 
demais gerentes locais, viabilizando o grupo. O encontro foi gravado, transcrito e realizamos a crônica a partir da síntese das falas e interpretação dos valores, comportamentos, conflitos e contradições que as permearam. $\mathrm{Na}$ análise utilizamos os conceitos estruturantes do referencial teórico como construtos norteadores da análise do material empírico oriundo do grupo.

\section{APRESENTAÇÃOE ANÁLISE DOS RESULTADOS}

Dos dezenove gerentes da Supervisão Técnica de Área, 10 participaram da pesquisa, ou seja, $52,63 \%$. Destes, $70 \%$ eram do sexo feminino e $30 \%$ do sexo masculino, sendo $40 \%$ médicos, $20 \%$ dentistas, $20 \%$ psicólogos, $10 \%$ fonoaudiólogos e $10 \%$ enfermeiros.

Em relação ao preparo para exercer a gerência, 50\% fizeram o curso de Gerenciamento de Unidades de Saúde (GE-RUS), $10 \%$ realizaram curso de gestão em outra Instituição e $40 \%$ não possuíam qualquer curso na área de gestão. Quanto ao tempo de exercício na função, $90 \%$ ocupavam essa posição entre 03-05 anos, 10\% assumiram há menos de 01 ano e somente $20 \%$ possuíam experiência em gestão em outro serviço, que não na Secretaria Municipal de Saúde. Quanto aos cursos de pós-graduação, $90 \%$ informaram ter realizado cursos nas suas áreas técnicas específicas e $10 \%$ que nunca realizaram qualquer curso de pós-graduação.

O primeiro tema emergente das entrevistas referiu-se aos conhecimentos gerenciais que os sujeitos julgavam ne-cessários ao gestor de Unidade Básica de Saúde para desempenhar o seu papel de maneira eficiente e eficaz. As percepções revelaram que estes deveriam conhecer: as propostas do SUS, a máquina administrativa, a população, a Unidade, o pessoal, a dinâmica das relações humanas, o potencial de cada funcionário e como trabalhar a interse-torialidade. Destacaram a necessidade de ter compromisso com a proposta da atenção básica; ter participado das propostas ou estar consciente das metas e prioridades da região e do município.

Comparando esses conhecimentos gerenciais considerados pelo grupo com os conhecimentos gerenciais abordados nos cursos de gestão das mais importantes Universidades do país, verificamos que nos cursos os conhecimentos básicos para fundamentação teórica do gestor convergem para os seguintes temas: estatística, economia, epidemiologia, sociologia, tecnologia da informação, teoria geral da administração, psicologia, legislação em saúde, políticas de saúde e outros que propiciam a instrumentalização mais específica como: administração financeira, contabilidade, administração de recursos humanos, logística, administração de recursos físicos e materiais.
Ao relacionarmos os conhecimentos considerados necessários pelos sujeitos da pesquisa e os conhecimentos propostos como necessários à formação de um gestor nos cursos pertinentes à área de gestão de serviços de saúde, fica patente o quanto os gerentes detêm uma visão simplista voltada para o objeto de suas práticas em comparação com um conjunto de conhecimentos específicos e mais abrangentes trabalhados na formação nos cursos específicos de gestão em saúde.

O segundo tema relacionou-se às habilidades gerenciais que eles julgavam que deveriam ser desenvolvidas pelo gerente a partir dos conhecimentos essenciais. As discussões no grupo apontaram para: capacidade de negociação com as instâncias externas da unidade, com a hierarquia superior e com a máquina administrativa; habilidade de diálogo com os funcionários e com a população; persistência para manter um projeto construido coletivamente mantendo clareza dos objetivos; manter-se atualizado tecnicamente e na sua área de atuação; ter jogo de cintura, flexibilidade para relacionar-se com a população e colegas da equipe; ter controle emocional e da maneira de se portar e de conduzir; ter habilidade para lidar com dados e interpretá-los e paciência.

Em relação às habilidades, apesar de o fazerem de maneira intuitiva sem ancoragem nos conhecimentos essenciais, muitas das citadas coincidiam com o referencial teórico utilizado como base neste estudo que aponta quais habilidades devem estar presentes no perfil de competências do gestor $^{(3,11-12)}$. No entanto, ressaltamos que habilidades devem ser desenvolvidas pela mobilização de conhecimentos adquiridos.

O terceiro tema discutido no grupo foi que atitudes devem permear as competências do gestor. Os resultados foram: ser mais democrático; conseguir ouvir, conviver e suportar o conflito; não ser muito personalista mas capaz de se preservar; ser claro para falar e saber ouvir o lado do funcionário; ter equilíbrio, bom senso e credibilidade; manter proximidade com a população; não ser ditador pois democracia propicia crescimento e fortalecimento; ser exemplo mantendo atitude respeitosa e coerente; ser pró-ativo e estimular isso na equipe; ser imparcial e justo; ser humilde; ser observador e interferir menos.

O conjunto de atitudes elencadas como importantes ao exercício da posição de gestor mostra-se coerente com o perfil de competências apontado pela literatura que subsidia as competências gerenciais ressaltando-se que essas devem ser compostas a partir do contexto do comportamento organizacional que representa o conjunto de valores éticos, morais e sociais aceitos pelo grupo de atores que participam dos processos da instituição ${ }^{(11-18)}$. 


\section{CONCLUSÕES}

Resgatando alguns elementos do construto teórico que dá sustentação ao presente estudo destacamos pesquisas sobre gestão e cultura organizacional na administração pública brasileira, que mostram que $70 \%$ dos gestores são centrados em tarefas, $23 \%$ em pessoas e apenas $7 \% \mathrm{em}$ tarefas e pessoas, demonstrando falta de atenção ao sistema social, que deve ser pano de fundo de todos os processos organizacionais ${ }^{(10)}$. Estudos apontam que os gestores considerados mais eficazes passam a maior parte do tempo administrando pessoas e tomando decisões com relação a elas e que, hoje em dia, o investimento no capital humano e nas relações é o aspecto mais valorizado para atingir resultados $^{(15-17)}$.

No contraponto, pesquisas apontam que as estruturas da administração pública conduzem à beira do caos devido a: lentidão dos processos decisórios; falta de delegação de poder; objetivos definidos no nível gerencial e que não são compartilhados com as chefias intermediárias e executores; falta de capacidade de análise de situações em relação aos ambientes interno e externo; falta de plano de carreiras; práticas de controle inadequadas ou inexistentes e a presença da organização informal como antagonista à formal ${ }^{(15-16)}$.

Essas pesquisas referendam que algumas tentativas de inovação gerencial na administração pública não contribuíram para reestruturar a organização do trabalho e não propiciaram a incorporação das concepções de qualidade dos sujeitos envolvidos nem alteraram as relações de poder existentes entre gerentes, funcionários e usuários. Porém verificou-se que as atitudes dos gerentes frente à inovação influenciaram as atitudes dos seus subordinados e que o modelo de administração burocrática em vigor em muitas instituições públicas é ainda de cunho patrimonialista, com o objetivo dominante de conquistar e manter espaços de $\operatorname{poder}^{(16-17)}$.

Tomando por base os estudos citados e os resultados da presente investigação se pode concluir que o gestor despreparado para tal é hoje um dos nós críticos do serviço público, pois propicia discrepâncias quanto à liderança necessária para conduzir processos de mudança e executar políticas de saúde, levando à manutenção de projetos que devem ser superados. É o que acontece nas diversas unidades pesquisadas. Assinala-se que construir competências para a gestão de Unidades Básicas de Saúde ainda é muito mais um projeto individual do gestor de buscar capacitação ou não do que uma política de recursos humanos do Estado ou Município que valorize esse desenvolvimento como essencial. Observa-se pelos resultados do presente estudo, que aqueles que mais precisariam desenvolver competências gerenciais são os que menos percebem ou valorizam essa necessidade.
Verificamos também que existe uma distância muito grande entre o que os gestores acreditam ser os conhecimentos gerenciais necessários a um gestor de Unidade Básica de Saúde e aqueles considerados conteúdos programáticos essenciais e que são desenvolvidos nos cursos de gestão em saúde. Outro aspecto verificado foi que independente de ter ou não participado de curso de capacitação em gestão, as rotinas do dia-a-dia dos gestores estudados pouco se modificaram. Uma hipótese formulada diz respeito ao fato da lógica política predominar em relação à lógica técnica que opera a condução de mudanças tanto assistenciais como gerenciais no sistema público.

O sistema ainda é regido predominantemente por princípios administrativos que se assemelham aos tradicionais e ultrapassados, devido à rigidez da mediação que deve ser mantida entre interlocutores interessados em diferentes projetos. Tal fato acarreta planejamentos e direcionamentos diferentes a serem implementados ao mesmo tempo pelos agentes da gerência no nível do meio com seus interlocutores, gerentes e agentes que atuam nos loci das práticas e que enfrentam as agruras de não poderem planejar as ações, passando o tempo todo improvisando e apagando incêndios, como referem os próprios sujeitos da pesquisa.

Isso, aliado ao desconhecimento do gerenciamento do tempo e do estresse, do gerenciamento de conflitos, do gerenciamento das mudanças e da falta de planejamento estratégico participativo com direcionamento uniforme, leva a referendar resultados obtidos em outras pesquisas que defendem que a demanda pela descrição de um perfil gerencial e pela capacitação devem vir juntos com novas práticas de organização do trabalho ${ }^{(18)}$.

Não se pode deixar de mencionar que há necessidade de redesenhar os macroprocessos e de entender que novas competências devem ser desenvolvidas para que haja condições de melhorar os serviços prestados à população no serviço público, especificamente nas Unidades Básicas de Saúde.

Quanto aos estudos que elencam as competências gerenciais, é possível apreender algumas que são de consenso entre os autores ${ }^{(2-3,11-12,18)}$ que se dedicam nacional e internacionalmente ao estudo do tema como: visão global (sistêmica e de longo prazo); comunicação eficaz; negociação e gerenciamento de conflitos; gerenciamento de mudanças; gerenciamento do tempo e do estresse; uso do processo decisório participativo; gestão de planos, ações e resultados; pensamento criativo; fomento de um ambiente produtivo de trabalho; ter responsabilidade ética e social, saber responsabilizar-se e comprometer-se.

Conhecer o perfil de competências dos atuais gestores de UBS de uma área tomada como amostra da SMS-SP permitiu concluir que as competências deles não favorecem a implementação dos novos modelos assistenciais e gerenciais 
que incluem estratégias que lhe são inerentes, tendo em vista que não se percebem e nem são reconhecidos pelo seu grupo de referência como líderança.

Os dados mostraram que a percepção dos atuais gerentes, em relação às competências para gerir as UBS, tende a uma visão simplista e que existe despreparo desses agentes para assumirem a posição. Assim sendo, defendemos que para haver a ascensão de profissionais à posição de gestor de uma Unidade Básica de Saúde ou a quaisquer serviços de saúde deveria ser instituído um sistema de avaliação de competências e certificação de formação profissional meritória, na qual cursos específicos de Gestão em Saúde fossem pré-requisitos. Isto porque se sabe que o despreparo do gestor influencia diretamente o modo de operacionalização das estratégias e a dinâmica das equipes envolvidas nos serviços podendo levar à ineficácia e ineficiência dos processos.

Com isso, apesar da limitação referente ao fato do cenário ter mostrado apenas uma pequena parte da complexidade e da diversidade das situações inerentes a um Município de porte gigantesco como São Paulo, consideramos que os resultados dessa investigação possam subsidiar políticas de recursos humanos que validem um perfil de competências gerenciais que seja mais favorável à consolidação de novos modelos de gestão em saúde em consonância com os novos modelos assistenciais almejados.

\section{REFERÊNCIAS}

1. São Paulo (Cidade). Secretaria Municipal de Saúde. Atenção Básica e PSF. Documento norteador: compromisso das Unidades Básicas de Saúde com a população. São Paulo; 2005.

2. Silva SF. Municipalização da saúde e poder local: sujeitos, atores e políticos [tese]. São Paulo: Faculdade de Saúde Pública, Universidade de São Paulo; 2001.

3. Fleury MTL, Oliveira Junior MM, organizadores. Gestão estratégica do conhecimento: integrando aprendizagem, conhecimento e competências. São Paulo: Atlas; 2001.

4. Junqueira LAP. Gerência dos serviços de saúde. In: Anais da Conferência Nacional de Saúde. Descentralizando e Democratizando o Conhecimento; 1992; Brasília, BR. v. 1.

5. Simões AR. Gestão Estratégica nas Organizações Públicas de Saúde: um estudo de caso da consolidação do SUS Municipal [dissertação]. São Paulo: Centro Universitário Álvares Penteado, UNIFECAP; 2003.

6. Ciampone MHT, Felli VEA, Castilho V, Kurcgant P . Resgate da produção do conhecimento na área de administração de serviços de enfermagem. Rev Esc Enferm USP. 2005;39(n.esp): $535-43$.

7. Breilh J, Granda E. La investigación de la salud en la sociedad. Quito: CEAS; 1981.

8. Gramigna MR. Modelo de competências e gestão dos talentos. São Paulo: Pearson Prentice Hall; 2007.

9. Minayo MCS. O desafio do conhecimento: pesquisa qualitativa em saúde. São Paulo: Hucitec; 1996.

10. Thiollent M. Metodologia da pesquisa-ação. $3^{\mathrm{a}}$ ed. São Paulo: Autores Associados; 1968.
11. Caproni PJ. Treinamento gerencial: como dar um salto significativo em sua carreira profissional. São Paulo: Makron Books; 2002.

12. Zarifian P. Objetivo e competência: por uma nova lógica. Trad. de Maria Helena C. V. Trylinki. São Paulo: Atlas; 2001.

13. Silveira CM. Pesquisa sobre gestão e cultura organizacional na administração pública brasileira [texto na Internet]. [citado 2005 dez. 17]. Disponível em: http://www.clovis.massaud.nom.br/ artigos $21 . h t m$

14. Drucker PF. O melhor de Peter Drucker: a administração. São Paulo: Nobel; 2002.

15. Marinho JA. Funcionários públicos de nível médio na administração do Município de São Paulo: uma pesquisa exploratória [dissertação]. São Paulo: Escola de Administração, Fundação Getúlio Vargas; 1996.

16. Mendes VLPS. Inovação gerencial na administração pública: um estudo na esfera municipal no Brasil [tese na Internet]. Salvador: Escola de Administração, Universidade Federal da Bahia; 2000. Salvador; 2000. [citado 2005 dez. 17]. Disponível em: http://www.adm.ufba.br/ipublica_teseveramendes.html

17. Santana JP. A gestão do trabalho nos estabelecimentos de saúde: elementos para uma proposta [texto na Internet]. [citado 2005 dez. 17]. Disponível em: http://www.opas.org.br/rh/ publicacoes/textos_apoio/pub04U3T6.pdf

18. Quinn RE, Thompson MP, Faerman SR, MacGrath M. Competências gerenciais: princípios e aplicações. Rio de Janeiro: Elsevier; 2003. 